\title{
Integration of Nanomaterials and Bioluminescence Resonance Energy Transfer Techniques for Sensing Biomolecules
}

\author{
Eugene Hwang ${ }^{1}$, Jisu Song ${ }^{1}$ and Jin Zhang ${ }^{1,2, * \mathbb{C}}$ \\ 1 School of Biomedical Engineering, University of Western Ontario, 1151 Richmond St., \\ London, ON N6A 5B9, Canada; ehwang8@uwo.ca (E.H.); jsong254@uwo.ca (J.S.) \\ 2 Department of Chemical and Biochemical Engineering, University of Western Ontario, 1151 Richmond St., \\ London, ON N6A 5B9, Canada \\ * Correspondence: jzhang@eng.uwo.ca; Tel.: +1-519-661-2111 (ext. 88322)
}

Received: 3 February 2019; Accepted: 12 March 2019; Published: 16 March 2019

check for updates

\begin{abstract}
Bioluminescence resonance energy transfer (BRET) techniques offer a high degree of sensitivity, reliability and ease of use for their application to sensing biomolecules. BRET is a distance dependent, non-radiative energy transfer, which uses a bioluminescent protein to excite an acceptor through the resonance energy transfer. A BRET sensor can quickly detect the change of a target biomolecule quantitatively without an external electromagnetic field, e.g., UV light, which normally can damage tissue. Having been developed quite recently, this technique has evolved rapidly. Here, different bioluminescent proteins have been reviewed. In addition to a multitude of bioluminescent proteins, this manuscript focuses on the recent development of BRET sensors by utilizing quantum dots. The special size-dependent properties of quantum dots have made the BRET sensing technique attractive for the real-time monitoring of the changes of target molecules and bioimaging in vivo. This review offers a look into the basis of the technique, donor/acceptor pairs, experimental applications and prospects.
\end{abstract}

Keywords: bioluminescence resonance energy transfer; fluorescent nanomaterials; fluorescent nanobiosensors; quantum dots

\section{Introduction}

Bioluminescence resonance energy transfer (BRET) sensors offer a high degree of sensitivity and reliability in a procedure that is both easy to perform and relatively expensive. BRET sensors utilize bioluminescence generated from a luciferase enzyme found in the sea pansy in order to donate energy to a fluorescence molecule that will emit a measurable quantity of fluorescence [1-3]. This system can be used to monitor an easily detectable light signal in real time with a high degree of sensitivity. BRET sensors present a less invasive and easier way to perform the modification of fluorescence resonance energy transfer (FRET), which requires an external light source to initiate the fluorescence transfer [4]. In studies that have previously utilized FRET, BRET can be an effective alternative. For example, in a study by Li et al., a FRET dye-labeled probe was used to improve single-base mismatch discrimination in DNA detection [5]. This technique is limited to in vitro applications due to the requirement of external illumination. By utilizing a BRET probe in the place of FRET, this DNA detection technique can be used in live animal models, thereby expanding the potential for this technique. FRET has been widely used in detecting protein-protein interactions [5-10]. One such study encountered problems in analyzing protein proximity in the endoplasmic reticulum of cells due to the overlap of the FRET emission wavelength and highly variable cellular autofluorescence [5]. 
This problem, termed bleed-through, was mitigated by the engineering of a new FRET pair which significantly increased the signal to noise ratio. However, this new FRET pair compromised its signal intensity. Such a problem could potentially be solved using BRET instead, which has been proven to mitigate the effects of cellular autofluorescence [11,12].

No longer requiring an external light source has made BRET attractive for use in biological systems, which may be susceptible to tissue autofluorescence and photobleaching. Background emission from tissue, otherwise known as autofluorescence, was found to be a limiting factor in the sensitivity of reporters $[13,14]$. Chemiluminescent resonance energy transfer (CRET) is another non-radiative energy transferring process in which the oxidization of a chemiluminescent compound excites an acceptor fluorophore [15-19]. The major advantages for those systems (CRET and BRET) are low background noise and high excitation efficiency, as there is no need for an extra excitation source, typically a high-energy laser. In this way, in particular, a quantum dots (QDs) based BRET system has showed great potential in deep tissue imaging with a low harmful effect on the body. Thus, the use of bioluminescent reporters has become increasingly attractive in biological applications.

BRET is a natural phenomenon involving the non-radiative energy transfer between a bioluminescent donor molecule and a fluorescent acceptor molecule. When the bioluminescent donor, typically an oxidative luciferase enzyme such as NLuc, emits bioluminescent energy, which excites the fluorescent acceptor and increases its emission [14,20], this is known as resonance energy transfer, and only occurs when the two proteins are within $10 \mathrm{~nm}$ (Figure 1). The changes in ratio of the acceptor to donor emissions are monitored, which are useful in studying protein-protein interactions (PPI) since the mechanism depends on distance $[4,14]$.

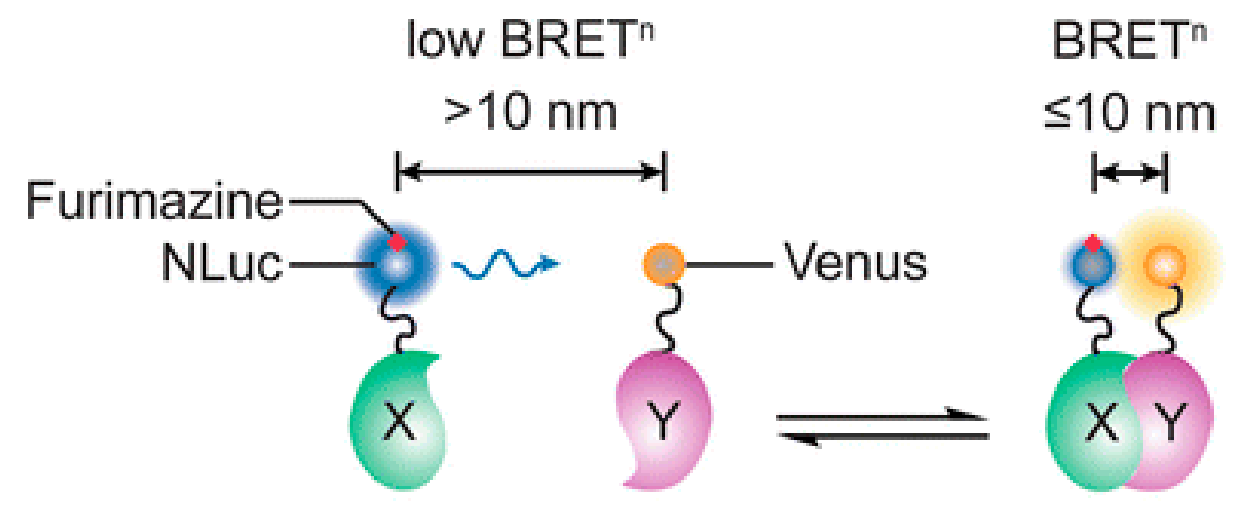

Figure 1. Schematic of a NLuc based BRET $\left(B^{2} \mathrm{~T}^{\mathrm{n}}\right)$ design. Nluc is the donor fluorphore and Venus is the acceptor fluorophore. Nluc and Venus are fused to their respective proteins of interest ( $X$ and $\mathrm{Y})$. BRET signal is detected when the proteins are in close proximity. Reprinted by permission from Springer Nature [14]. Copyright 2016.

FRET and, by extension, BRET, is a distance dependent mechanism. The efficiency of the energy transfer $(E)$ is defined as the quantum yield of the energy transfer transition [21]. The efficiency depends on the distance between the donor and acceptor, usually up to $10 \mathrm{~nm}$. In addition, the emission spectrum of the donor should overlap with the acceptor's absorption spectrum. The donor emission dipole moment and the acceptor absorption dipole moment should be relatively oriented [22,23]. The efficiency is calculated as follows:

$$
E=\frac{R_{0}^{6}}{R_{0}^{6}+r^{6}}
$$

where $r$ is the distance between the donor and acceptor and $R_{0}$ is the Förster distance of the donor acceptor pair which is the distance where $E=50 \%$. 
The Förster distance is given by the following equation:

$$
R_{0}=0.21\left[\kappa^{2} Q_{D} n^{-4} J(\lambda)\right]^{\frac{1}{6}}
$$

where $J(\lambda)$ is the spectral overlap between donor emission and acceptor absorption, $Q_{D}$ is the quantum yield of the donor, $n$ is the refractive index of the medium, and $\kappa^{2}$ is an orientation factor related to the relative orientation of the donor emission and acceptor absorption dipole moments.

BRET has revolutionized the detection of small molecules and PPIs. Some techniques utilize a quenching mechanism whereby the acceptor molecule accepts the fluorescence of the donor molecule and quenches the signal. In one particular sensor, gold nanoparticles were used to quench the bioluminescence from RLuc [24]. When the sensor was bound to glucose, the gold nanoparticles could no longer quench the signal, therefore bioluminescence was restored (Figure 2). The intensity of the signal could then be correlated to the concentration of the glucose in a sample.

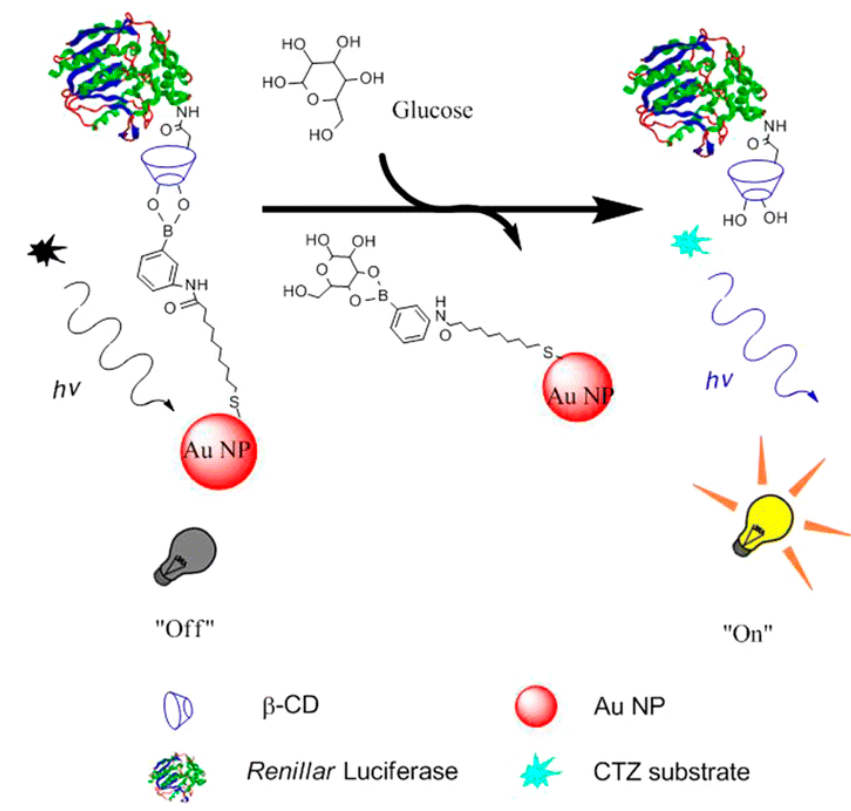

Figure 2. Schematic illustration of bioluminescence quenching-based nanosensor in glucose sensing. Reprinted with permission from [24]. Copyright Springer Nature 2017.

There exists a variety of bioluminescence donors, many of which are derived from naturally occurring enzymes in animals such as the firefly or the sea pansy. Among the different donors, each have clear advantages and disadvantages in certain applications. Therefore, certain donors are considered for certain tasks according to their properties. This review aims to highlight some of the differences between the donors and how they can be applied in BRET constructs.

Typically, BRET sensors utilize fluorescent proteins [3,5,25-27] or organic dyes [28-30] as acceptors. However, recent studies report the use of nanoparticles such as quantum dots (QD) to be effective. QDs have the advantage of adjustable emission depending on size, superior brightness, high photostability, and multiplexing [31,32]. Fluorescent semiconductor quantum dots were previously limited in their application for in vivo imaging due to requiring excitation from an external source of light [5-8]. Combining QDs with luminescence provided by bioluminescent proteins has provided opportunities for in vivo imaging [7]. This review will offer some insight into the many applications of BRET-QDs.

\section{Bioluminescent Proteins}

Table 1 provides a summary on the different bioluminescent proteins. The detailed information of each bioluminescent protein has been described as follows. 
Table 1. Summary of Bioluminescent proteins.

\begin{tabular}{llcl}
\hline \multicolumn{1}{c}{ Name } & \multicolumn{1}{c}{ Size (kDa) } & Emission (nm) & \multicolumn{1}{c}{ Substrate } \\
\hline Aequorin & 22 & 469 & Coelenterazine \\
\hline Bacterial luciferase (Lux) & $\begin{array}{l}\text { Alpha subunit: } 40 \\
\text { Beta subunit: 35 }\end{array}$ & 490 & $\begin{array}{l}\text { FMNH } \\
\text { long-chain aliphatic aldehyde }\end{array}$ \\
\hline Firefly luciferase (Fluc) & 61 & 562 & D-luciferin \\
\hline Renilla luciferase (Rluc) & 36 & 480 & Coelenterazine \\
\hline Gaussia luciferase (Gluc) & 19.9 & 480 & Coelenterazine \\
\hline $\begin{array}{l}\text { Vargula luciferase (Vluc) or } \\
\text { Cypridina luciferase }\end{array}$ & 62 & 460 & Vargulin (Cypridina luciferin) \\
\hline Metridia luciferase & 24 & 480 & Coelenterazine \\
\hline Nano luciferase (Nluc) & 19 & 460 & Furimazine \\
\hline
\end{tabular}

\subsection{Aequorin}

First discovered in the jellyfish Aequorea victoria, aequorin is a $22 \mathrm{kDa}$ photoprotein that emits blue light at $469 \mathrm{~nm}$ when exposed to its substrate, coelenterazine [33,34]. Given its high sensitivity for calcium, aequorin is most often used to detect calcium concentration from a single cell by expressing it using recombinant aequorin [35-37]. Typically, aequorin is recombined with polyols to increase its stability [37]. Addition of coelenterazine to the medium allows it to passively diffuse into the cell, and aequorin emits blue light in proportion to the calcium levels within the cell [34]. However, aequorin gives a low light quantum yield compared to other bioluminescent proteins [34]. Furthermore, its substrate, coelenterazine, has been shown to be unstable and have poor biodistribution [38].

\subsection{Bacterial Luciferase}

Bacterial luciferase (Lux) consists of two subunit: alpha, which is $40 \mathrm{kDa}$, and beta, which is $35 \mathrm{kDa}$; it emits blue light, which peaks at $490 \mathrm{~nm}[39,40]$. Lux is an ATP dependent luciferase and requires oxygen and NADPH as cofactor, in order to work on its substrate: long-chain aliphatic aldehydes and flavin mononucleotide (FMNH2) [39,40]. It is most often used as a bacterial reporter, more specifically in luminous bacteria for an autonomous bioluminescence oxidation reaction [40]. The long-chain aliphatic aldehydes have shown to be able to freely diffuse through the cell membrane and have high binding affinity for Lux [39]. Like aequorin, Lux demonstrates a poor light quantum yield as well as lack of thermostability [41]. Furthermore, studies are limited to the luminous bacteria due to the cytotoxicity of aldehydes [42].

\subsection{Firefly Luciferase}

Firefly luciferase (Fluc), the first luciferase to be discovered, is a $61 \mathrm{kDa}$ protein that emits blue light at $562 \mathrm{~nm}$ when exposed to its substrate, D-luciferin [43-45]. Similar to Lux, Fluc is ATP-dependent and requires the presence of co-factors, oxygen and magnesium, in order to complete its reaction with D-luciferin [44-46]. Since its discovery, Fluc has been used in various fields as a biosensor through recombination with another protein of interest and as ATP sensor, taking advantage of its ATP-dependency [47-49]. Fluc demonstrates high light quantum yield making it superior in comparison to Lux and aequorin [45]. Nonetheless, disadvantages involving Fluc as well as D-luciferin has emerged. Although D-luciferin had been presumed to have good biodistribution given its ability to cross the blood-brain barrier and blood-placental barrier, recent studies have discovered its low tissue permeability, which results in heterogenous biodistribution [38,50,51]. Furthermore, D-luciferin has low affinity for Fluc, which may result in false negative signals [38]. Moreover, Fluc and D-luciferin only gives a single imaging signal limiting studies to a single molecular event or a single population 
of cells [38]. Finally, the large size of Fluc may lead to steric hindrance when used as a recombinant protein [46].

\subsection{Renilla Luciferase}

Renilla luciferase (Rluc), first discovered in sea pansy, Renialla reniformis, is a $36 \mathrm{kDa}$ protein that emits blue light at $480 \mathrm{~nm}$ when worked with its substrate, coelenterazine [52-54]. Rluc is often used as a marker for gene expression in mammalian cells and as a biosensor when recombined with a protein of interest $[53,55]$. As it originates from non-mammalian cells, the gene sequence for Rluc includes codons that are uncommon in mammalian cells, which limits Rluc expression in the cells [52]. Furthermore, Rluc has shown to have low enzymatic turnover and quantum yield when compared to Fluc $[54,56]$. In addition, the problem of instability and poor biodistribution of coelenterazine remains [38].

\subsection{Gaussia Luciferase}

Gaussia luciferase (Gluc) is similar to Rluc as they both have emission peak at $480 \mathrm{~nm}$, are ATP-independent, and work on the same substrate, coelenterazine $[46,54,56]$. On the contrary, Gluc is smaller than Rluc at $19.9 \mathrm{kDa}$ and originates from Gaussia princeps eliminating the problem of uncommon codons [56]. Gluc has been used as a bioluminescent label for in vitro hybridization assay as well as a biosensor through recombination with another protein of interest $[46,57]$. Gluc is naturally secreted by the cells, which allows for it to be detectable in cell medium [56,58]. It has also been characterized to be more sensitive compared to Fluc and Rluc [58]. Despite its sensitivity, quantum yield remains low and problems involving coelenterazine ensues [38,54,59].

\subsection{Vargula Luciferase}

Vargula luciferase (Vluc), also known as Cypridina luciferase, is a $62 \mathrm{kDa}$ protein that emits blue light at $460 \mathrm{~nm}$ when worked with its substrate, vargulin, also known as cypridina luciferin [60-62]. Similar to Rluc, Vluc has been used as a marker for gene expression in mammalian cells as well as a biosensor when recombined with another protein of interest [61,63]. Also similar, to Gluc, Vluc is also naturally secreted by cells, and it is detectable in cell medium [63]. One advantage of Vluc over other luciferases is its glow-type bioluminescence compared to flash-type exhibited by other luciferases [62]. Previously Vluc has been shown to be difficult to express and purify from bacterial systems; however, the issue has been successfully addressed by using a truncated derivative of Vluc, which shows a higher degree of expression and purification while retaining its enzymatic activity [62].

\subsection{Metridia Luciferase}

Like Rluc and Gluc, Metridia luciferase also emits blue light at $480 \mathrm{~nm}$, is ATP-independent, and works on the same substrate, coelenterazine $[54,57,64]$. Smaller than Gluc but bigger than Rluc, metridia luciferase is $24 \mathrm{kDa}$ protein [64]. Similar to all luciferase, metridia luciferase has been used as a biosensor by recombining it with another protein of interest [64]. Metridia luciferase is also naturally secreted by cells similar to Vluc and Gluc [57]. In addition, its low molecular mass serves as an advantage in recombination [64]. However, Metridia luciferase demonstrates low quantum yield, and the disadvantages of coelenterazine discussed before stays relevant [38,54].

\subsection{Nano Luciferase}

Nano Luciferase (Nluc) is a recently developed luciferase that uses furimazine as a substrate to emit blue light at $460 \mathrm{~nm}$ [65-67]. It is the one of the smallest luciferase to be characterized at $19 \mathrm{kDa}$ and has the one of the brightest bioluminescence to date [65,67]. Not many studies using Nluc have been published compared to other bioluminescent proteins as the molecule is fairly new; the published studies typically use Nluc as a biosensor through recombination with their protein 
of interest $[67,68]$. Nluc exhibits glow type bioluminescence, similar to Vluc, with long half-life of approximately $2 \mathrm{~h}[65,67]$. Furthermore, furimazine has shown to exhibit lower background noise when compared to coelenterazine [46].

\section{QD-Based Biosensors by Applying Bioluminescent Resonance Energy Transfer Techniques}

Photoluminescent QDs are rapidly becoming popular choices for use in biomedical applications such as labeling, bioimaging, and biosensing. QDs are particularly appealing due to their high photostability, continuous absorption spectra, and size-dependent fluorescence [31,32,69-71]. QDs are typically synthesized as hydrophobic and therefore require a number of modifications in order to be suitable in biological environments. Modifying QDs to be suitable for solubility in water results in a decreased quantum yield and therefore requires surface modifications [72,73]. There exist three strategies to make QDs water soluble: ligand exchange, silanization, and encapsulation.

In ligand exchange, the original hydrophobic coating is replaced by a water-soluble bifunctional molecule. Once attached to the QD surface, a hydrophilic tail makes the QDs able to bioconjugate, usually with other surface groups such as thiol, amine and carboxyl [74].

Silanization is an extension of ligand exchange where the QD is coated in a silica shell which is non-toxic, chemically inert and optically transparent. The silica shell protects the QD from oxidization and provides a matrix which enhances stability in the environment. The silica is biocompatible and can be functionalized for bioconjugation [75-77].

Encapsulation utilizes different carriers such as amphiphilic polymers, polymeric microbeads, and liposomes [78-80]. These coating molecules have hydrophobic and hydrophilic units, therefore can interact strongly with the QD surface and the aqueous outside environment [78]. Liposomes are particularly popular due to their porous spherical structure and high loading capacity [25,79]. However, they are limited due to susceptibility to temperature and $\mathrm{pH}$ changes [81].

There are two primary approaches to bind biomolecules onto the surface of QDs. Non-covalent which is mediated by interactions between the biomolecules and the QD surface, and covalent linking which is achieved through chemical reactions of molecular surface groups [80,82].

Non-covalent binding is achieved through two types of interaction; electrostatic interaction between oppositely charged molecules and high affinity secondary interactions. QDs are negatively charged on the surface, therefore can be electrostatically coupled to positively charged proteins $[80,83]$. High affinity secondary interactions are interactions between functional groups on the surface of the QD and the biomolecule. Biotin-avidin is a commonly utilized combination, though limited by the increased size of the product $[83,84]$. The interaction between His-tagged biomolecules and Ni-NTA is widely used in bioconjugation and often used for developing a QD probe for performing Western blot analyses $[83,84]$.

Covalent binding involves the reaction between functional groups on QDs and biomolecules. Crosslinkers can be used to bind the molecules. Zero-length crosslinkers such as EDC and DCC are used because they will not add anymore atoms [11]. Carboxylic functionalized QDs are among the most popular due to the abundance of free amine groups on proteins which is can conjugate with [12]. The most popular method utilizes EDC which mediates the formation of an amide bond between the carboxyl on QDs and amines on biomolecules $[11,85]$.

\subsection{QD-Based BRET Sensor for Detecting Biomolecules}

Carboxylated quantum dots (Qd-625) were conjugated to a DNA probe (Qd-D-P) while oligonucleotide probes were conjugated to Rluc (Rluc-P). The sensing scheme uses the two antisense oligonucleotide sequences which will anneal adjacent to each other in a head-to-head fashion when the target is present (Figure 3). The maximum BRET signal was obtained by optimizing the spacing between the Rluc-P and Qd-D-P when hybridized to the target. Optimization was done using oligonucleotide targets, which create various separation distances. The optimal separation distance was found to be 15 nucleotides. Hybridization time between labeled probes and target was studied and found 
the optimal time to be $5 \mathrm{~min}$ and $35 \mathrm{~min}$. In conclusion, an on-type, BRET-based sensing platform incorporating Rluc and QD with a 5-min detection time of a nucleic acid target in vitro was developed. The method was also determined to be highly sensitive (detection limit of $0.54 \mathrm{pmol}$ ) and selective against mismatch targets [86].

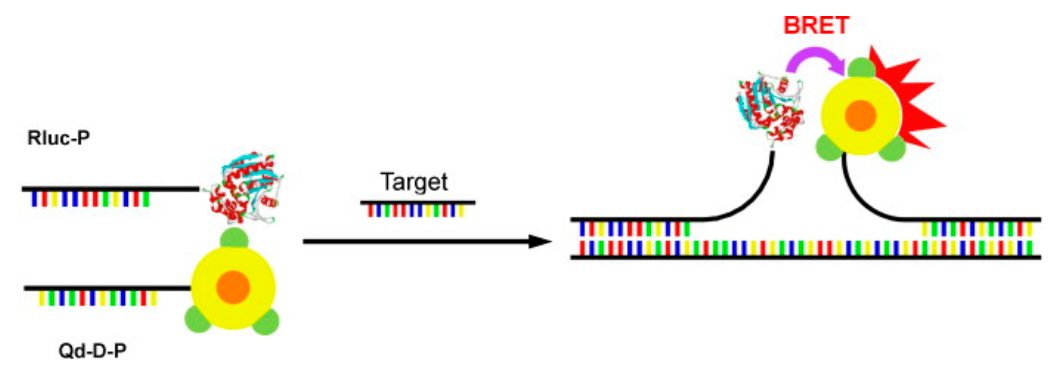

Figure 3. Schematic of BRET based on-type sensing system. The Rluc-P and Qd-D-P hybridized to the target in head-to-head fashion permitting BRET between Rluc and Qd. Reprinted from [55], with permission from Elsevier.

Near-infrared region optical detection of apoptotic cells was achieved using BRET-coupled annexin V-functionalized quantum dots. A recombinant protein with Rluc and annexin V was conjugated to glutathione-coated CdSeTe/CdS QDs (Figure 4A). Annexin V recognizes phosphatidylserine (PS) on the outer monolayer of the membrane of apoptotic cells and binds to it in the presence of $\mathrm{Ca}^{2+}$ ions (Figure 4B). The QDs act as a probe for detecting apoptotic cells with a peak emission at $830 \mathrm{~nm}$ and a high quantum yield of $61 \%$ in aqueous solution. This method was presented as a simple, rapid, and efficient method for synthesizing a BRET-induced NIR emission probe and with its low phototoxicity could prove to be useful in highly sensitive detection of apoptotic cells in vivo and in vitro [87].

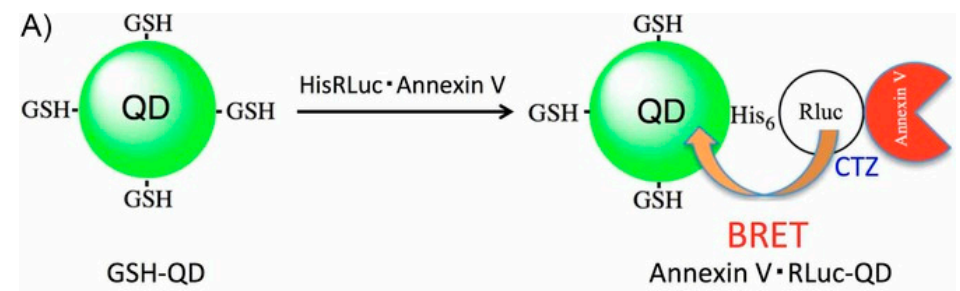

B)

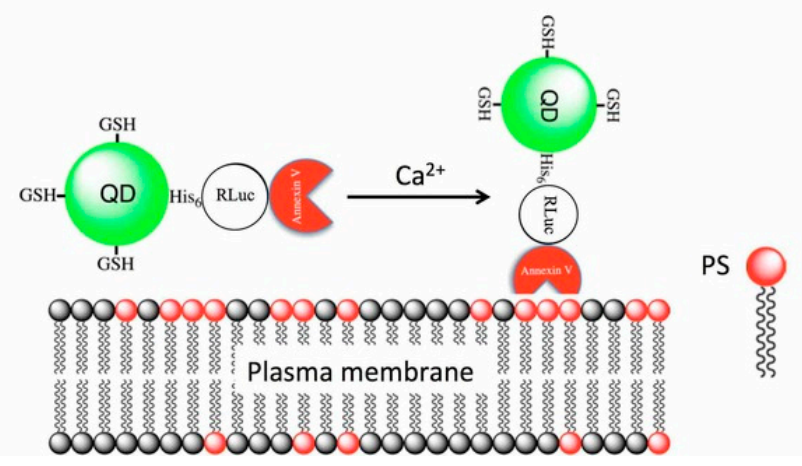

Figure 4. (A) Synthetic method for the preparation of recombinant protein (HisRLuc-annexin V)-conjugated QDs (annexin V-Rluc-QDs). (B) Schematic representation for the binding of annexin V-RLuc-QDs to PS on plasma membrane of apoptotic cells in the presence of $\mathrm{Ca}^{2+}$ ions. Reprinted with permission from [56]. Copyright 2017 John Wiley and Sons.

A general BRET homogenous immunoassay was developed for the determination of small molecules. This assay is based on QDs and Rluc which produce variable energy transfer in the presence of different concentrations of free fluoroquinolones (FQs). In the absence of free FQs, QDs conjugated to 
norfloxacin (QD-NOR) are recognized by a single-chain variable fragment (scFv), which is conjugated to Rluc, and are able to produce an energy transfer (Figure 5). Otherwise, the presence of Free FQs prevents the Rluc and QDs from producing and energy transfer. Similar results for cross-reactivity to seven representative FQs were found when compared to an enzyme-linked immunosorbent assay (ELISA). The LOD of the QD-BRET immunoassay was $2.54 \mathrm{ng} / \mathrm{L}$ with a linear range which covers 4 orders of magnitude $(0.023 \mathrm{ng} / \mathrm{mL}$ to $25.60 \mathrm{ng} / \mathrm{mL})$. The use of QDs enables the flexibility of more choices for donor substrates given the wider excitation range of the QDs. The authors noted that by replacing the target of interest, the immunosensor could be used with a variety of other small molecules and could open up the possibility of multiplex detection using different QDs [88].
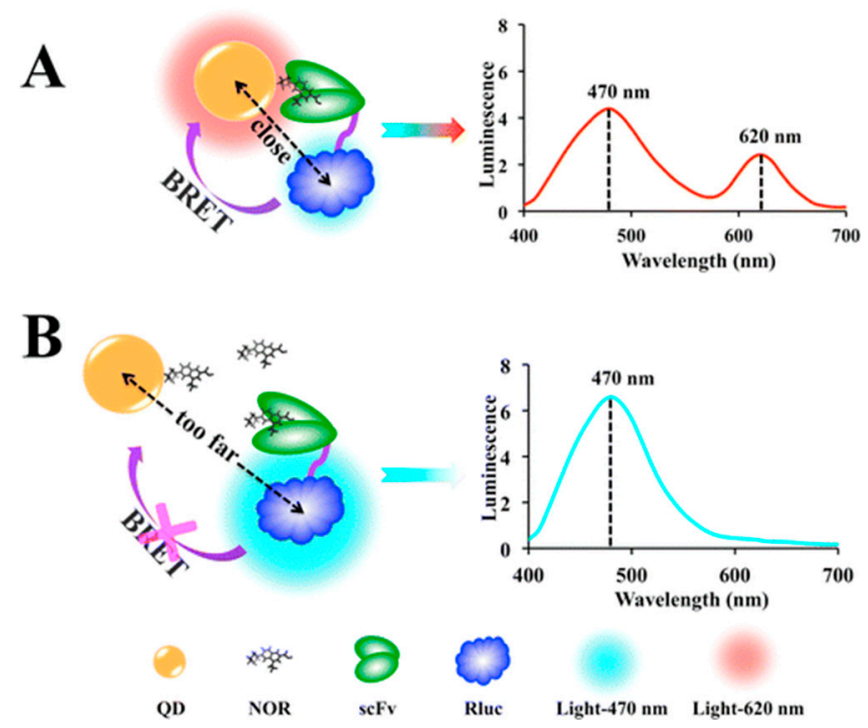

Figure 5. (A) In the absence of free FQs, QD-NOR is recognized by scFv-Rluc and the Rluc and QDs are in close proximity; energy is released from the substrate and transferred to the QDs via BRET. (B) In the presence of free FQs, the scFv-Rluc binds to the free FQs and the distance between the Rluc and QDs is too far to realize energy transfer. Reprinted with permission from [57]. Copyright 2016 American Chemical Society.

In one particular study, CdSe/ZnS core-shell quantum dots (QD705) were conjugated to Nluc (Figure 6). This construct was used to image tumors by conjugating it to cyclic arginine-glycine-aspartic acid (cRGD) peptides, which were selected due to their having a strong affinity for integrin $\alpha_{\mathrm{v}} \beta_{3}$ which are known to be expressed on various tumor types. When intradermally injected into the hind paw of a mouse, the popliteal lymph nodes could be visualized by bioluminescence at 5 min post injection (p.i.) without any background signal. To demonstrate tumor targeting capabilities, the sensor was injected into mice with integrin expressing U87MG human glioblastoma cell tumors. After $2 \mathrm{~h}$ p.i. organs were harvested and ex vivo imaging found a noticeably visible signal in the tumors injected with QD-Nluc-cRGD. When compared to traditional fluorescence techniques, bioluminescence demonstrated higher sensitivity due to the distance dependent relationship of BRET components. Using the BRET conjugate, the tumor to background ratio was exceptionally high (>85) [89]. 

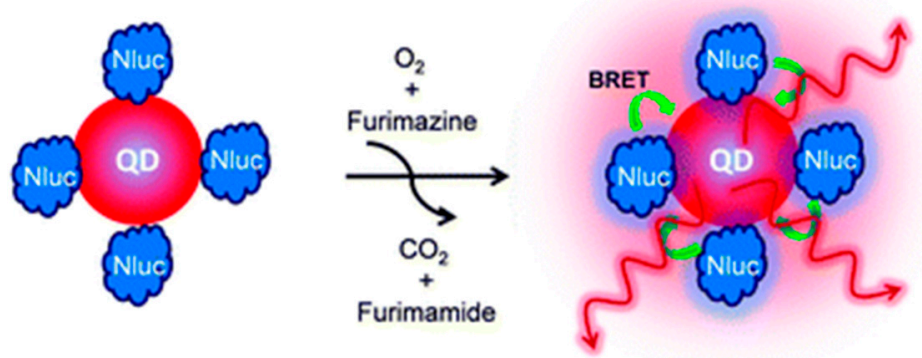

Figure 6. QD-Nluc-cRGD conjugate. Chemical communications by Royal Society of Chemistry (Great Britain) Reproduced with permission of ROYAL SOCIETY OF CHEMISTRY in the format Journal/magazine via Copyright Clearance Center.

\subsection{QD-Based BRET Sensor Used in Bioimaging In Vivo}

BRET-QD nanoparticles were applied to in vivo lymphatic imaging in mice. QD655 covalently linked to Luc8 protein, an eight-mutation variant of Rluc, were intracutaneously injected into 10 weak old normal athymic female mice at different sites, the chin, ear and paws. After $5 \mathrm{~min}$, the imaging was carried out (Figure 7). Using BRET-QD655 has the advantage over traditional bioluminescence imaging (BLI) in that NIR light emission is more favorable in tissue penetration. All lymph nodes were visualized when injected with BRET-QD655 constructs and since there is no excitation light, the BRET signal more accurately represents the concentration of the quantum dots in the lymph nodes, leading to better quantitative imaging [90].

(a)

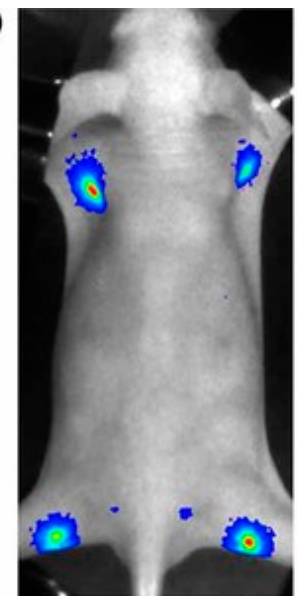

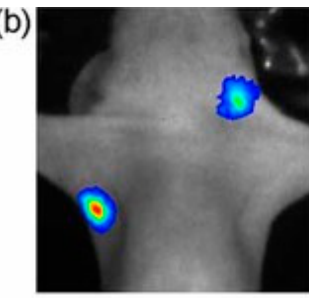
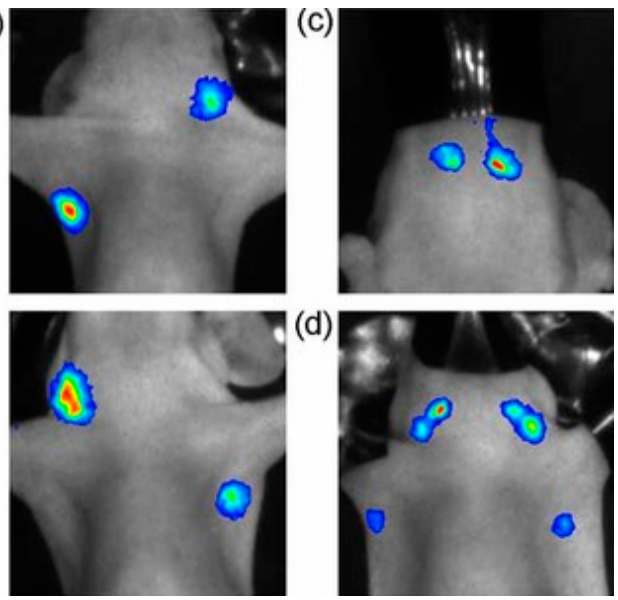

Figure 7. BRET lymphatic images of different lymphatic basins. BRET-QD655 were injected at all four paws (a), the ear and forepaw (b), the chin (c), or five different sites (d) both forepaws, both ears and chin). Reprinted with permission from [59]. Copyright 2011 John Wiley and Sons.

The use of QD nanoparticles as a tool for non-invasive investigation of mammalian spermatozoa was explored. $655 \mathrm{~nm}$ emitting CdSe/ZnS QD nanoparticles were conjugated to nona-Arginine R9 peptide which facilitates cellular internalization. The QDs were linked to RLuc and used to label boar spermatozoa and were assessed for changes in sperm motility, viability, and fertilizing potential. In vitro assays concluded no adverse effect of the BRET-QD on the spermatozoa. The results suggest the strong potential for a novel imaging technique for tracking BRET-QD labeled spermatozoa to better understand sperm migration within the female genital tract [91]. 


\subsection{Other QDs-Based Applications}

Previous studies have demonstrated the potential for low level laser for treatment (LLLT) of Alzheimer's disease. LLLT has proven to be effective in mitigating amyloid- $\beta$ peptide induced oxidative stress and inflammation. However, this technique is limited by penetration depth in live animals and human subjects. In a study by Bungart et al., quantum dots in a BRET conjugate were employed as a source of near infrared light (NIR) [92]. $800 \mathrm{~nm}$-emitting BRET-QDs activated with colenterazine were used to pre-treat primary cortical rat astrocytes. When the astrocytes were exposed to $5 \mu \mathrm{M}$ amyloid- $\beta$ for $2 \mathrm{~h}$, light treated cells had reductions in amyloid- $\beta$ induced superoxide anion production (Figure 8) and inflammatory marker expression to untreated control levels. Using BRET-QDs or coelenterazine individually resulted in reductions that were not statistically significant. NIR light cannot penetrate further than a few centimeters [92] therefore BRET-QDs offer a promising alternative for non-invasive LLLT for Alzheimer's disease.
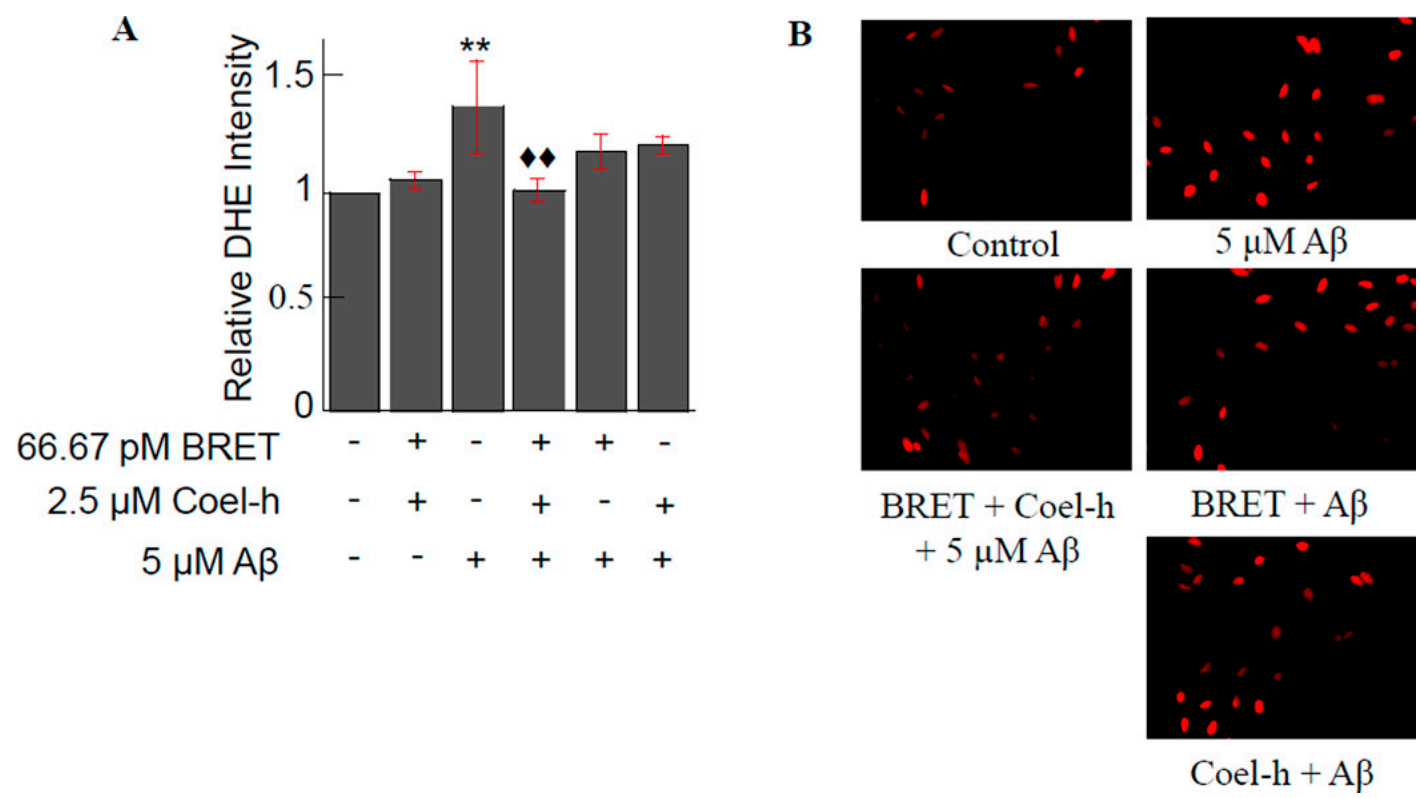

Figure 8. BRET-QD with coel-h pretreatment on A $\beta$-induced superoxide anions production. (A) A $\beta$ treatment increased the fluorescent intensity of DHE by $40 \%$ as compared to control. The pretreatment of BRET-QD $(66.7 \mathrm{pM})$ and coel-h $(2.5 \mu \mathrm{M})$ suppressed the A $\beta$-induced increase in superoxide anion production back to that of control. Both the BRET-QD and Coel-h alone pretreatment lowered $A \beta$-induced superoxide anion, but not with a statistical significance. (B) Fluorescence images representing each experimental group. Each experiment was repeated three timesas compared to $5 \mu \mathrm{M}$ $\mathrm{A} \beta$. Data of each treatment group were normalized by the control for each independent experiment prior to statistical analysis. Reprinted from [92], with permission from Elsevier.

\section{Biocompatibility}

Quantum dots cores consist of various metal complexes which have raised questions about their application in a biological setting [93]. This concern is commonly resolved by adding organic coatings such as methoxy-polyethylene glycol (PEG) to the surface in order to increase biocompatibility [94]. Commonly used quantum dots include CdTe and CdSe and all of these metals are known to be toxic to humans when exposed upon degradation of the quantum dots [95-99]. There is lack of biocompatibility data for quantum dots and little research done on the effect on humans. Part of the reason can be attributed to the various factors related to physicochemical properties of quantum dots like size, charge, concentration, outer coating and mechanical stability $[100,101]$. Various studies have found adverse effects due to quantum dots [102] and some have found little to no adverse effects, given some modifications $[103,104]$. Studies have determined that quantum dots have a significantly long 
half-life and the degradation of fluorescent particles taking almost 12 weeks in the liver [94,105]. This uncertainty in the biocompatibility warrants further investigation, particularly in human subjects.

\section{Conclusions}

Owing to the quick development of luminescence nanomaterials and bioluminescence proteins, BRET sensing technology benefits from the conjugation of these two cutting edge materials. QDs offer unparalleled function in their high intensity, stability, broad emission and narrow emission spectra, size and tunable emission. Along with a wealth of bioluminescent proteins with properties to suit a wide range of applications, BRET-QD sensors demonstrate a high potential for applications ranging from protein-protein interaction to biomolecule detection. Though the biocompatibility of QDs has yet to be proven, there are existing techniques to increase their viability in biological settings.

In conclusion, BRET in conjunction with quantum dots is very promising for in vivo applications despite uncertainty in its biocompatibility. It is a far more effective alternative to traditional FRET methods, and with sufficient research can be used for a wide range of applications in imaging and nanomedicine.

Author Contributions: E.H. is the first author who wrote over $60 \%$ manuscript, and J.S. worked with E.H. on this manuscript, and wrote over $40 \%$ manuscript. J.Z. initiated the idea of the review paper, provided the structure of the manuscript, and made revision of the manuscript.

Funding: E.H. and J.S. received the Western Graduate Research Scholarship. J.Z. received the grant from Natural Sciences and Engineering Research Council of Canada (NSERC).

Conflicts of Interest: The authors declare no conflict of interest.

\section{References}

1. Morin, J.G.; Hastings, J.W. Energy transfer in a bioluminescent system. J. Cell. Physiol. 1971, 77, 313-318. [CrossRef] [PubMed]

2. Ward, W.W.; Cormier, M.J. An energy transfer protein in coelenterate bioluminescence. Characterization of the Renilla green-fluorescent protein. J. Biol. Chem. 1979, 254, 781-788. [PubMed]

3. Lorenz, W.W.; McCann, R.O.; Longiaru, M.; Cormier, M.J. Isolation and expression of a cDNA encoding Renilla reniformis luciferase. Proc. Natl. Acad. Sci. USA 1991, 88, 4438-4442. [CrossRef] [PubMed]

4. Förster, T. Zwischenmolekulare Energiewanderung und Fluoreszenz. Ann. Phys. 1948, 437, 55-75. [CrossRef]

5. Li, H.; Luo, Y.; Sun, X. Fluorescence resonance energy transfer dye-labeled probe for fluorescence-enhanced DNA detection: An effective strategy to greatly improve discrimination ability toward single-base mismatch. Biosens. Bioelectron. 2011, 27, 167-171. [CrossRef]

6. Prada, M.P.; Syed, A.U.; Buonarati, O.R.; Reddy, G.R.; Nystoriak, M.A.; Ghosh, D.; Simo, S.; Sato, D.; Sasse, K.C.; Ward, S.M.; et al. A Gs-coupled purinergic receptor boosts $\mathrm{Ca}\left({ }^{2+}\right)$ influx and vascular contractility during diabetic hyperglycemia. Elife 2019, 8, e42214. [CrossRef]

7. Greotti, E.; Capitanio, P.; Wong, A.; Pozzan, T.; Pizzo, P.; Pendin, D. Familial Alzheimer's disease-linked presenilin mutants and intracellular $\mathrm{Ca}\left({ }^{2+}\right)$ handling: A single-organelle, FRET-based analysis. Cell Calcium 2019, 79, 44-56. [CrossRef]

8. Solis, C.; Russell, B. CapZ integrates several signaling pathways in response to mechanical stiffness. J. Gen. Physiol. 2019, 151. [CrossRef]

9. Zhang, L.; Bouadjel, K.; Manoury, B.; Vandecasteele, G.; Fischmeister, R.; Leblais, V. Cyclic nucleotide signalling compartmentation by phosphodiesterases in cultured vascular smooth muscle cells. Br. J. Pharmacol. 2019. [CrossRef]

10. Manoharan, G.B.; Kopra, K.; Eskonen, V.; Härmä, H.; Abankwa, D. High-throughput amenable fluorescence-assays to screen for calmodulin-inhibitors. Anal. Biochem. 2019, 18, 31185-31190. [CrossRef]

11. Pfleger, K.D.G.; Eidne, K.A. Illuminating insights into protein-protein interactions using bioluminescence resonance energy transfer (BRET). Nat. Methods 2006, 3, 165-174. [CrossRef] [PubMed]

12. del Rosal, B.; Benayas, A. Strategies to Overcome Autofluorescence in Nanoprobe-Driven In Vivo Fluorescence Imaging. Small Methods 2018, 2, 1800075. [CrossRef] 
13. So, M.-K.; Xu, C.; Loening, A.M.; Gambhir, S.S.; Rao, J. Self-illuminating quantum dot conjugates for in vivo imaging. Nat. Biotechnol. 2006, 24, 339. [CrossRef] [PubMed]

14. Troy, T.; Jekic-McMullen, D.; Sambucetti, L.; Rice, B. Quantitative Comparison of the Sensitivity of Detection of Fluorescent and Bioluminescent Reporters in Animal Models. Mol. Imaging 2004, 3, 9-23. [CrossRef] [PubMed]

15. Huang, X.; Li, L.; Qian, H.; Dong, C.; Ren, J. A Resonance Energy Transfer between Chemiluminescent Donors and Luminescent Quantum-Dots as Acceptors (CRET). Angew. Chem. Int. Ed. 2006, 45, 5140-5143. [CrossRef]

16. Zhao, S.; Huang, Y.; Shi, M.; Liu, R.; Liu, Y.-M. Chemiluminescence Resonance Energy Transfer-Based Detection for Microchip Electrophoresis. Anal. Chem. 2010, 82, 2036-2041. [CrossRef] [PubMed]

17. Freeman, R.; Liu, X.Q.; Willner, I. Chemiluminescent and Chemiluminescence Resonance Energy Transfer (CRET) Detection of DNA, Metal Ions, and Aptamer-Substrate Complexes Using Hemin/G-Quadruplexes and CdSe/ZnS Quantum Dots. J. Am. Chem. Soc. 2011, 133, 11597-11604. [CrossRef] [PubMed]

18. Liu, X.Q.; Freeman, R.; Golub, E.; Willner, I. Chemiluminescence and Chemiluminescence Resonance Energy Transfer (CRET) Aptamer Sensors Using Catalytic Hemin/G-Quadruplexes. ACS Nano 2011, 5, 7648-7655. [CrossRef] [PubMed]

19. Ward, W.W.; Cormier, M.J. Energy Transfer via Protein-Protein Interaction In Renilla Bioluminescence. Photochem. Photobiol. 1978, 27, 389-396. [CrossRef]

20. Mo, X.-L.; Fu, H. BRET: NanoLuc-Based Bioluminescence Resonance Energy Transfer Platform to Monitor Protein-Protein Interactions in Live Cells. Methods Mol. Biol. 2016, 1439, 263-271.

21. Schaufele, F.; Demarco, I.; Day, R.N. FRET Imaging in the Wide-Field Microscope. In Molecular Imaging; Periasamy, A., Day, R.N.B.T.-M.I., Eds.; American Physiological Society: San Diego, CA, USA, 2005; pp. $72-94$.

22. Ansbacher, T.; Srivastava, H.K.; Stein, T.; Baer, R.; Merkx, M.; Shurki, A. Calculation of transition dipole moment in fluorescent proteins-Towards efficient energy transfer. Phys. Chem. Chem. Phys. 2012, 14, 4109-4117. [CrossRef] [PubMed]

23. Hsu, C.-Y.; Chen, C.-W.; Yu, H.-P.; Lin, Y.-F.; Lai, P.-S. Bioluminescence resonance energy transfer using luciferase-immobilized quantum dots for self-illuminated photodynamic therapy. Biomaterials 2013, 34, 1204-1212. [CrossRef] [PubMed]

24. Chen, L.; Chen, L.; Dotzert, M.; Melling, C.W.J.; Zhang, J. Nanostructured biosensor using bioluminescence quenching technique for glucose detection. J. Nanobiotechnol. 2017, 15, 59. [CrossRef]

25. Hoshino, H.; Nakajima, Y.; Ohmiya, Y. Luciferase-YFP fusion tag with enhanced emission for single-cell luminescence imaging. Nat. Methods 2007, 4, 637. [CrossRef] [PubMed]

26. Iglesias, P.; Costoya, J.A. A novel BRET-based genetically encoded biosensor for functional imaging of hypoxia. Biosens. Bioelectron. 2009, 24, 3126-3130. [CrossRef]

27. Rumyantsev, K.A.; Turoverov, K.K.; Verkhusha, V. V Near-infrared bioluminescent proteins for two-color multimodal imaging. Sci. Rep. 2016, 6, 36588. [CrossRef] [PubMed]

28. Kojima, R.; Takakura, H.; Ozawa, T.; Tada, Y.; Nagano, T.; Urano, Y. Rational Design and Development of Near-Infrared-Emitting Firefly Luciferins Available In Vivo. Angew. Chem. Int. Ed. 2012, 52, 1175-1179. [CrossRef]

29. Wu, C.; Mino, K.; Akimoto, H.; Kawabata, M.; Nakamura, K.; Ozaki, M.; Ohmiya, Y. In vivo far-red luminescence imaging of a biomarker based on BRET from Cypridina bioluminescence to an organic dye. Proc. Natl. Acad. Sci. USA 2009, 106, 15599-15603. [CrossRef]

30. Branchini, B.R.; Ablamsky, D.M.; Rosenberg, J.C. Chemically Modified Firefly Luciferase Is an Efficient Source of Near-Infrared Light. Bioconjugate Chem. 2010, 21, 2023-2030. [CrossRef]

31. De, A. The New Era of Bioluminescence Resonance Energy Transfer Technology. Curr. Pharm. Biotechnol. 2011, 12, 558-568. [CrossRef]

32. Xia, Z.; Rao, J. Biosensing and imaging based on bioluminescence resonance energy transfer. Curr. Opin. Biotechnol. 2009, 20, 37-44. [CrossRef]

33. Mithöfer, A.; Mazars, C. Aequorin-based measurements of intracellular $\mathrm{Ca}^{2+}$-signatures in plant cells. Biol. Proc. Online 2002, 4, 105-118. [CrossRef] [PubMed]

34. Lim, D.; Bertoli, A.; Sorgato, M.C.; Moccia, F. Generation and usage of aequorin lentiviral vectors for $\mathrm{Ca}^{2+}$ measurement in sub-cellular compartments of hard-to-transfect cells. Cell Calcium 2016, 59, 228-239. [CrossRef] [PubMed] 
35. Cobbold, P.H.; Cuthbertson, K.S.; Goyns, M.H.; Rice, V. Aequorin measurements of free calcium in single mammalian cells. J. Cell Sci. 1983, 61, 123-136. [PubMed]

36. Granatiero, V.; Patron, M.; Tosatto, A.; Merli, G.; Rizzuto, R. The use of aequorin and its variants for $\mathrm{Ca}^{2+}$ measurements. Cold Spring Harb. Protoc. 2014, 2014, 9-16. [CrossRef] [PubMed]

37. Zeinoddini, M.; Khajeh, K.; Hosseinkhani, S.; Saeedinia, A.R.; Robatjazi, S.-M. Stabilisation of Recombinant Aequorin by Polyols: Activity, Thermostability and Limited Proteolysis. Appl. Biochem. Biotechnol. 2013, 170, 273-280. [CrossRef] [PubMed]

38. Iwano, S.; Sugiyama, M.; Hama, H.; Watakabe, A.; Hasegawa, N.; Kuchimaru, T.; Tanaka, K.Z.; Takahashi, M.; Ishida, Y.; Hata, J.; et al. Single-cell bioluminescence imaging of deep tissue in freely moving animals. Science 2018, 359, 935-939. [CrossRef]

39. Waidmann, M.S.; Bleichrodt, F.S.; Laslo, T.; Riedel, C.U. Bacterial luciferase reporters: The Swiss army knife of molecular biology. Bioeng. Bugs 2011, 2, 8-16. [CrossRef] [PubMed]

40. Ke, D.; Tu, S.-C. Activities, Kinetics and Emission Spectra of Bacterial Luciferase-Fluorescent Protein Fusion Enzymes. Photochem. Photobiol. 2011, 87, 1346-1353. [CrossRef] [PubMed]

41. Cui, B.; Zhang, L.; Song, Y.; Wei, J.; Li, C.; Wang, T.; Wang, Y.; Zhao, T.; Shen, X. Engineering an Enhanced, Thermostable, Monomeric Bacterial Luciferase Gene As a Reporter in Plant Protoplasts. PLoS ONE 2014, 9, e107885. [CrossRef]

42. Hollis, R.P.; Lagido, C.; Pettitt, J.; Porter, A.J.R.; Killham, K.; Paton, G.I.; Glover, L.A. Toxicity of the bacterial luciferase substrate, $\mathrm{n}$-decyl aldehyde, to Saccharomyces cerevisiae and Caenorhabditis elegans. FEBS Lett. 2001, 506, 140-142. [CrossRef]

43. Coleman, S.M.; McGregor, A. A bright future for bioluminescent imaging in viral research. Future Virol. 2015, 10, 169-183. [CrossRef]

44. $\quad$ de Wet, J.R.; Wood, K.V.; DeLuca, M.; Helinski, D.R.; Subramani, S. Firefly luciferase gene: Structure and expression in mammalian cells. Mol. Cell. Biol. 1987, 7, 725-737. [CrossRef] [PubMed]

45. Lundin, A. Optimization of the Firefly Luciferase Reaction for Analytical Purposes. In Bioluminescence: Fundamentals and Applications in Biotechnology-Volume 2; Thouand, G., Marks, R., Eds.; Advances in Biochemical Engineering/Biotechnology; Springer: Berlin/Heidelberg, Germany, 2014; pp. 31-62.

46. Gibbons, A.E.; Luker, K.E.; Luker, G.D. Dual Reporter Bioluminescence Imaging with NanoLuc and Firefly Luciferase BT. In Reporter Gene Imaging: Methods and Protocols; Dubey, P., Ed.; Springer: New York, NY, USA, 2018; pp. 41-50.

47. Branchini, B.R.; Southworth, T.L.; Fontaine, D.M.; Kohrt, D.; Welcome, F.S.; Florentine, C.M.; Henricks, E.R.; DeBartolo, D.B.; Michelini, E.; Cevenini, L.; et al. Red-emitting chimeric firefly luciferase for in vivo imaging in low ATP cellular environments. Anal. Biochem. 2017, 534, 36-39. [CrossRef] [PubMed]

48. Wang, W.; Zhao, Q.; Luo, M.; Li, M.; Wang, D.; Wang, Y.; Liu, Q. Immobilization of Firefly Luciferase on PVA-co-PE Nanofibers Membrane as Biosensor for Bioluminescent Detection of ATP. ACS Appl. Mater. Interfaces 2015, 7, 20046-20052. [CrossRef] [PubMed]

49. Smirnova, D.V.; Ugarova, N.N. Firefly Luciferase-based Fusion Proteins and their Applications in Bioanalysis. Photochem. Photobiol. 2017, 93, 436-447. [CrossRef]

50. Adams, S.T.; Miller, S.C. Beyond D-luciferin: Expanding the Scope of Bioluminescence Imaging in vivo. Curr. Opin. Chem. Biol. 2014, 21, 112-120. [CrossRef]

51. Simonyan, H.; Hurr, C.; Young, C.N. A synthetic luciferin improves in vivo bioluminescence imaging of gene expression in cardiovascular brain regions. Physiol. Genom. 2016, 48, 762-770. [CrossRef]

52. Paulmurugan, R.; Gambhir, S.S. Monitoring Protein-Protein Interactions Using Split Synthetic Renilla Luciferase Protein-Fragment-Assisted Complementation. Anal. Chem. 2003, 75, 1584-1589. [CrossRef]

53. Bhaumik, S.; Gambhir, S.S. Optical imaging of Renilla luciferase reporter gene expression in living mice. Proc. Natl. Acad. Sci. USA 2002, 99, 377-382. [CrossRef]

54. Eremeeva, E.V.; Markova, S.V.; Vysotski, E.S. Highly active BRET-reporter based on yellow mutant of Renilla muelleri luciferase. Dokl. Biochem. Biophys. 2013, 450, 147-150. [CrossRef] [PubMed]

55. Lorenz, W.W.; Cormier, M.J.; O'Kane, D.J.; Hua, D.; Escher, A.A.; Szalay, A.A. Expression of the Renilla reniformis luciferase gene in mammalian cells. J. Biolumin. Chemilumin. 1996, 11, 31-37. [CrossRef]

56. Tannous, B.A.; Kim, D.-E.; Fernandez, J.L.; Weissleder, R.; Breakefield, X.O. Codon-Optimized Gaussia Luciferase cDNA for Mammalian Gene Expression in Culture and in Vivo. Mol. Ther. 2005, 11, 435-443. [CrossRef] 
57. Stepanyuk, G.A.; Xu, H.; Wu, C.-K.; Markova, S.V.; Lee, J.; Vysotski, E.S.; Wang, B.-C. Expression, purification and characterization of the secreted luciferase of the copepod Metridia longa from Sf9 insect cells. Protein Expr. Purif. 2008, 61, 142-148. [CrossRef]

58. Inoue, Y.; Sheng, F.; Kiryu, S.; Watanabe, M.; Ratanakanit, H.; Izawa, K.; Tojo, A.; Ohtomo, K. Gaussia Luciferase for Bioluminescence Tumor Monitoring in Comparison with Firefly Luciferase. Mol. Imaging 2011, 10, 377-385. [CrossRef]

59. Degeling, M.H.; Bovenberg, M.S.S.; Lewandrowski, G.K.; de Gooijer, M.C.; Vleggeert-Lankamp, C.L.A.; Tannous, M.; Maguire, C.A.; Tannous, B.A. Directed molecular evolution reveals Gaussia luciferase variants with enhanced light output stability. Anal. Chem. 2013, 85, 3006-3012. [CrossRef]

60. Thompson, E.M.; Nagata, S.; Tsuji, F.I. Cloning and expression of cDNA for the luciferase from the marine ostracod Vargula hilgendorfii. Proc. Natl. Acad. Sci. USA 1989, 86, 6567-6571. [CrossRef]

61. Thompson, E.M.; Nagata, S.; Tsuji, F.I. Vargula hilgendorfii luciferase: A secreted reporter enzyme for monitoring gene expression in mammalian cells. Gene 1990, 96, 257-262. [CrossRef]

62. Hunt, E.A.; Moutsiopoulou, A.; Broyles, D.; Head, T.; Dikici, E.; Daunert, S.; Deo, S.K. Expression of a soluble truncated Vargula luciferase in Escherichia coli. Protein Expr. Purif. 2017, 132, 68-74. [CrossRef]

63. Tanahashi, Y.; Ohmiya, Y.; Honma, S.; Katsuno, Y.; Ohta, H.; Nakamura, H.; Honma, K.I. Continuous measurement of targeted promoter activity by a secreted bioluminescence reporter, Vargula hilgendorfii luciferase. Anal. Biochem. 2001, 289, 260-266. [CrossRef]

64. Markova, S.V.; Golz, S.; Frank, L.A.; Kalthof, B.; Vysotski, E.S. Cloning and Expression of cDNA for a Luciferase from the Marine Copepod Metridia longa A NOVEL SECRETED BIOLUMINESCENT REPORTER ENZYME. J. Biol. Chem. 2004, 279, 3212-3217. [CrossRef]

65. Song, G.; Wu, Q.-P.; Xu, T.; Liu, Y.-L.; Xu, Z.-G.; Zhang, S.-F.; Guo, Z.-Y. Quick preparation of nanoluciferase-based tracers for novel bioluminescent receptor-binding assays of protein hormones: Using erythropoietin as a model. J. Photochem. Photobiol. B Biol. 2015, 153, 311-316. [CrossRef] [PubMed]

66. Hall, M.P.; Unch, J.; Binkowski, B.F.; Valley, M.P.; Butler, B.L.; Wood, M.G.; Otto, P.; Zimmerman, K.; Vidugiris, G.; Machleidt, T.; et al. Engineered Luciferase Reporter from a Deep Sea Shrimp Utilizing a Novel Imidazopyrazinone Substrate. ACS Chem. Biol. 2012, 7, 1848-1857. [CrossRef] [PubMed]

67. He, S.-X.; Song, G.; Shi, J.-P.; Guo, Y.-Q.; Guo, Z.-Y. Nanoluciferase as a novel quantitative protein fusion tag: Application for overexpression and bioluminescent receptor-binding assays of human leukemia inhibitory factor. Biochimie 2014, 106, 140-148. [CrossRef] [PubMed]

68. Li, J.; Guo, Z.; Sato, T.; Yuan, B.; Ma, Y.; Qian, D.; Zhong, J.; Jin, M.; Huang, P.; Che, L.; et al. Optimized application of the secreted Nano-luciferase reporter system using an affinity purification strategy. PLOS ONE 2018, 13, e0196617. [CrossRef]

69. Wu, Y.; Chakrabortty, S.; Gropeanu, R.A.; Wilhelmi, J.; Xu, Y.; Er, K.S.; Kuan, S.L.; Koynov, K.; Chan, Y.; Weil, T. pH-Responsive Quantum Dots via an Albumin Polymer Surface Coating. J. Am. Chem. Soc. 2010, 132, 5012-5014. [CrossRef]

70. Liu, H.-B.; Yan, Q.; Wang, C.; Liu, X.; Wang, C.; Zhou, X.-H.; Xiao, S.-J. Saccharide- and temperature-responsive polymer brushes grown on gold nanoshells for controlled release of diols. Colloids Surfaces A Physicochem. Eng. Asp. 2011, 386, 131-134. [CrossRef]

71. Song, F.; Tang, P.S.; Durst, H.; Cramb, D.T.; Chan, W.C.W. Nonblinking Plasmonic Quantum Dot Assemblies for Multiplex Biological Detection. Angew. Chem. Int. Ed. 2012, 51, 8773-8777. [CrossRef] [PubMed]

72. Gill, R.; Zayats, M.; Willner, I. Semiconductor quantum dots for bioanalysis. Angew. Chem. Int. Ed. Engl. 2008, 47, 7602-7625. [CrossRef] [PubMed]

73. Alivisatos, A.P.; Gu, W.; Larabell, C. Quantum dots as cellular probes. Annu. Rev. Biomed. Eng. 2005, 7, 55-76. [CrossRef]

74. Gerion, D.; Pinaud, F.; Williams, S.C.; Parak, W.J.; Zanchet, D.; Weiss, S.; Alivisatos, A.P. Synthesis and Properties of Biocompatible Water-Soluble Silica-Coated CdSe/ZnS Semiconductor Quantum Dots. J. Phys. Chem. B 2001, 105, 8861-8871. [CrossRef]

75. Aubert, T.; Soenen, S.J.; Wassmuth, D.; Cirillo, M.; Van Deun, R.; Braeckmans, K.; Hens, Z. Bright and Stable CdSe/CdS@SiO2 Nanoparticles Suitable for Long-Term Cell Labeling. ACS Appl. Mater. Interfaces 2014, 6, 11714-11723. [CrossRef] 
76. Aubert, T.; Grasset, F.; Mornet, S.; Duguet, E.; Cador, O.; Cordier, S.; Molard, Y.; Demange, V.; Mortier, M.; Haneda, H. Functional silica nanoparticles synthesized by water-in-oil microemulsion processes. J. Colloid Interface Sci. 2010, 341, 201-208. [CrossRef]

77. Selvan, S.T.; Tan, T.T.; Ying, J.Y. Robust, Non-Cytotoxic, Silica-Coated CdSe Quantum Dots with Efficient Photoluminescence. Adv. Mater. 2005, 17, 1620-1625. [CrossRef]

78. De, A.; Loening, A.M.; Gambhir, S.S. An improved bioluminescence resonance energy transfer strategy for imaging intracellular events in single cells and living subjects. Cancer Res. 2007, 67, 7175-7183. [CrossRef] [PubMed]

79. Venisnik, K.M.; Olafsen, T.; Loening, A.M.; Iyer, M.; Gambhir, S.S.; Wu, A.M. Bifunctional antibody-Renilla luciferase fusion protein for in vivo optical detection of tumors. Protein Eng. Des. Sel. 2006, 19, 453-460. [CrossRef] [PubMed]

80. Dacres, H.; Michie, M.; Wang, J.; Pfleger, K.D.G.; Trowell, S.C. Effect of enhanced Renilla luciferase and fluorescent protein variants on the Forster distance of Bioluminescence resonance energy transfer (BRET). Biochem. Biophys. Res. Commun. 2012, 425, 625-629. [CrossRef]

81. Alam, R.; Karam, L.M.; Doane, T.L.; Coopersmith, K.; Fontaine, D.M.; Branchini, B.R.; Maye, M.M. Probing Bioluminescence Resonance Energy Transfer in Quantum Rod-Luciferase Nanoconjugates. ACS Nano 2016, 10, 1969-1977. [CrossRef]

82. Nie, S.; Emory, S.R. Probing Single Molecules and Single Nanoparticles by Surface-Enhanced Raman Scattering. Science 1997, 275, 1102-1106. [CrossRef] [PubMed]

83. Bishop, K.J.M.; Wilmer, C.E.; Soh, S.; Grzybowski, B.A. Nanoscale forces and their uses in self-assembly. Small 2009, 5, 1600-1630. [CrossRef]

84. Valentini, F.; Carbone, M.; Palleschi, G. Carbon nanostructured materials for applications in nano-medicine, cultural heritage, and electrochemical biosensors. Anal. Bioanal. Chem. 2013, 405, 451-465. [CrossRef]

85. Wang, C.; Gao, X.; Su, X. In vitro and in vivo imaging with quantum dots. Anal. Bioanal. Chem. 2010, 397, 1397-1415. [CrossRef] [PubMed]

86. Kumar, M.; Zhang, D.; Broyles, D.; Deo, S.K. A rapid, sensitive, and selective bioluminescence resonance energy transfer (BRET)-based nucleic acid sensing system. Biosens. Bioelectron. 2011, 30, 133-139. [CrossRef] [PubMed]

87. Tsuboi, S.; Jin, T. Bioluminescence Resonance Energy Transfer (BRET)-coupled Annexin V-functionalized Quantum Dots for Near-Infrared Optical Detection of Apoptotic Cells. ChemBioChem 2017, 18, 2231-2235. [CrossRef] [PubMed]

88. Yu, X.; Wen, K.; Wang, Z.; Zhang, X.; Li, C.; Zhang, S.; Shen, J. General Bioluminescence Resonance Energy Transfer Homogeneous Immunoassay for Small Molecules Based on Quantum Dots. Anal. Chem. 2016, 88, 3512-3520. [CrossRef] [PubMed]

89. Kamkaew, A.; Sun, H.; England, C.G.; Cheng, L.; Liu, Z.; Cai, W. Quantum dot-NanoLuc bioluminescence resonance energy transfer enables tumor imaging and lymph node mapping in vivo. Chem. Commun. 2016, 52, 6997-7000. [CrossRef]

90. Kosaka, N.; Mitsunaga, M.; Bhattacharyya, S.; Miller, S.C.; Choyke, P.L.; Kobayashi, H. Self-illuminating in vivo lymphatic imaging using a bioluminescence resonance energy transfer quantum dot nano-particle. Contrast Media Mol. Imaging 2011, 6, 55-59. [CrossRef]

91. Feugang, J.M.; Youngblood, R.C.; Greene, J.M.; Fahad, A.S.; Monroe, W.A.; Willard, S.T.; Ryan, P.L. Application of quantum dot nanoparticles for potential non-invasive bio-imaging of mammalian spermatozoa. J. Nanobiotechnol. 2012, 10, 45. [CrossRef]

92. Bungart, B.L.; Dong, L.; Sobek, D.; Sun, G.Y.; Yao, G.; Lee, J.C.M. Nanoparticle-emitted light attenuates amyloid- $\beta$-induced superoxide and inflammation in astrocytes. Nanomed. Nanotechnol. Biol. Med. 2014, 10, 15-17. [CrossRef]

93. Dabbousi, B.O.; Rodriguez-Viejo, J.; Mikulec, F.V.; Heine, J.R.; Mattoussi, H.; Ober, R.; Jensen, K.F.; Bawendi, M.G. (CdSe)ZnS Core-Shell Quantum Dots: Synthesis and Characterization of a Size Series of Highly Luminescent Nanocrystallites. J. Phys. Chem. B 1997, 101, 9463-9475. [CrossRef]

94. Yang, R.S.H.; Chang, L.W.; Wu, J.-P.; Tsai, M.-H.; Wang, H.-J.; Kuo, Y.-C.; Yeh, T.-K.; Yang, C.S.; Lin, P. Persistent Tissue Kinetics and Redistribution of Nanoparticles, Quantum Dot 705, in Mice: ICP-MS Quantitative Assessment. Environ. Health Perspect. 2007, 115, 1339-1343. [CrossRef] 
95. Widy-Tyszkiewicz, E.; Piechal, A.; Gajkowska, B.; Śmiałek, M. Tellurium-induced cognitive deficits in rats are related to neuropathological changes in the central nervous system. Toxicol. Lett. 2002, 131, 203-214. [CrossRef]

96. Vinceti, M.; Wei, E.T.; Malagoli, C.; Bergomi, M.; Vivoli, G. Adverse health effects of selenium in humans. Rev. Environ. Health 2001, 16, 233-251. [CrossRef]

97. UMEMURA, T. Experimental reproduction of itai-itai disease, a chronic cadmium poisoning of humans, in rats and monkeys. Jpn. J. Vet. Res. 2000, 48, 15-28.

98. Klaassen, C.D.; Liu, J. Role of Metallothionein in Cadmium-Induced Hepatotoxicity and Nephrotoxicity. Drug Metab. Rev. 1997, 29, 79-102. [CrossRef] [PubMed]

99. Bertin, G.; Averbeck, D. Cadmium: Cellular effects, modifications of biomolecules, modulation of DNA repair and genotoxic consequences (a review). Biochimie 2006, 88, 1549-1559. [CrossRef] [PubMed]

100. Sukhanova, A.; Bozrova, S.; Sokolov, P.; Berestovoy, M.; Karaulov, A.; Nabiev, I. Dependence of Nanoparticle Toxicity on Their Physical and Chemical Properties. Nanoscale Res. Lett. 2018, 13, 44. [CrossRef] [PubMed]

101. Hardman, R. A Toxicologic Review of Quantum Dots: Toxicity Depends on Physicochemical and Environmental Factors. Environ. Health Perspect. 2006, 114, 165-172. [CrossRef]

102. Xu, G.; Lin, G.; Lin, S.; Wu, N.; Deng, Y.; Feng, G.; Chen, Q.; Qu, J.; Chen, D.; Chen, S.; et al. The Reproductive Toxicity of CdSe/ZnS Quantum Dots on the in vivo Ovarian Function and in vitro Fertilization. Sci. Rep. 2016, 6, 37677. [CrossRef]

103. Liu, J.; Yang, C.; Liu, J.; Hu, R.; Hu, Y.; Chen, H.; Law, W.-C.; Swihart, M.T.; Ye, L.; Wang, K.; et al. Effects of Cd-based Quantum Dot Exposure on the Reproduction and Offspring of Kunming Mice over Multiple Generations. Nanotheranostics 2017, 1, 23-37. [CrossRef]

104. Reyes-Esparza, J.; Martínez-Mena, A.; Gutiérrez-Sancha, I.; Rodríguez-Fragoso, P.; de la Cruz, G.G.; Mondragón, R.; Rodríguez-Fragoso, L. Synthesis, characterization and biocompatibility of cadmium sulfide nanoparticles capped with dextrin for in vivo and in vitro imaging application. J. Nanobiotechnol. 2015, 13, 83. [CrossRef] [PubMed]

105. Bargheer, D.; Giemsa, A.; Freund, B.; Heine, M.; Waurisch, C.; Stachowski, G.M.; Hickey, S.G.; Eychmüller, A.; Heeren, J.; Nielsen, P. The distribution and degradation of radiolabeled superparamagnetic iron oxide nanoparticles and quantum dots in mice. Beilstein J. Nanotechnol. 2015, 6, 111-123. [CrossRef] [PubMed]

(C) 2019 by the authors. Licensee MDPI, Basel, Switzerland. This article is an open access article distributed under the terms and conditions of the Creative Commons Attribution (CC BY) license (http:/ / creativecommons.org/licenses/by/4.0/). 